\title{
As imagens femininas n'O Vulgarizador: público de ciência e mulheres no século XIX
}

\author{
Female images in O Vulgarizador: science's public and women \\ in the nineteenth century
}

\author{
Moema de Rezende \\ Vergara \\ Pesquisadora adjunta do Museu \\ de Astronomia e Ciências Afins \\ Rua Mário Portela, 161 \\ apto. 1002 , bloco A \\ 22241-000 Rio de Janeiro - RJ - \\ Brasil \\ moema@mast.br
}

VERGARA, Moema de Rezende. As imagens femininas n'O Vulgarizador: público de ciência e mulheres no século XIX. História, Ciências, Saúde Manguinhos, Rio de Janeiro, v.15, supl., p.191-208, jun. 2008.

Este artigo analisa uma série de imagens de mulheres no periódico brasileiro $O$ Vulgarizador, veiculado no século XIX e dedicado à divulgação da ciência no Brasil. A análise das imagens ajuda a perceber questões que permeavam esse tipo de publicação: a presença dos Estados Unidos como modelo de progresso e desenvolvimento industrial; a relevância das Exposições Internacionais; as transformações da sociedade brasileira; e a adequação do papel feminino nesse processo.

Palavras-chave: gênero; ciência e tecnologia; imprensa; Brasil; século XIX.

VERGARA, Moema de Rezende. Female images in O Vulgarizador: science's public and women in the nineteenth century. História, Ciências, Saúde - Manguinhos, Rio de Janeiro, v.15, Suppl., p.191-208, June 2008.

The article examines images of women in the periodical $\mathrm{O}$ Vulgarizador, which sought to bring science into the public forum in nineteenth-century Brazil. An analysis of these images helps us recognize some of the issues of ongoing concern in the magazine: the United States as a model of progress and industrial development, the importance of World Fairs, and transformations in Brazilian society and women's role therein.

Keywords: gender; science and technology; press; Brazil; $19^{\text {th }}$ Century. 
$\mathrm{P}$ ara quem quer compreender a relação entre ciência e cultura, é preciso ver como o mundo da ciência extravasa para outras esferas e se manifesta em várias instâncias da vivência humana. A sociedade moderna é testemunha de um conjunto de atividades relativas à ciência, as quais não ocorrem necessariamente nos espaços institucionais. Talvez por isso mesmo seja fundamental verificar nesses outros locais as várias determinações entre cultura e ciência.

As revistas científico-literárias que circulavam no Brasil no final do século XIX constituem uma das diversas formas de compreensão da interface entre ciência e cultura. Caracterizadas pela ausência de vínculo institucional, as publicações divulgavam uma visão mais ampliada da prática científica sem se prender ao caráter disciplinar, como acontecia com os Arquivos do Museu Nacional, a Revista do IHGB ou a Revista do Observatório Nacional, apenas para citar alguns periódicos que conviveram com $O$ Vulgarizador. Tal generalidade articulava-se com a missão de 'traduzir' o conhecimento científico para o público em geral, contribuindo para sua circulação em diversos âmbitos da sociedade. O desejo de uma comunicação clara, composta de elementos que possibilitassem uma rápida interação com o(a) leitor(a) não especializado (a), carregava consigo as cores fortes do contexto social. Vale lembrar que esse contexto é resultado das diversas relações sociais, entre elas a de gênero.

No final da década de 1990, Evely Fox Keller afirmou que o campo de estudo dedicado à relação entre gênero e ciência dividir-se-ia basicamente em três linhas de investigação: "mulheres na ciência, construções científicas de gênero e influência do gênero nas construções históricas da ciência" (Fox Keller, 2001, citado em Lopes, jul.-dez. 2006, p.41). $\mathrm{O}$ presente trabalho se inscreve nesta última categoria, uma vez que pretende utilizar a categoria de gênero como caminho de análise das expectativas e dos indícios de comportamento do público de ciência no Brasil oitocentista.

No âmbito de nossa pesquisa mais ampla sobre a história da divulgação de ciência, deparamos com O Vulgarizador: Jornal dos Conhecimentos Úteis (1877-1880), que chamou a atenção primeiramente por ser uma publicação científico-literária ilustrada, o que nos levaria a refletir sobre a relação entre gênero, ciência e público. $O$ jornal foi fundado por Augusto Emílio Zaluar, que assumia o compromisso de trazer em cada número uma gravura. A publicação teve 38 números e 37 ilustrações. Neste trabalho construímos um subgrupo temático de dez gravuras. Diferentemente de outras publicações seriadas que circularam no século XIX, como a Revista Ilustrada, a Revista Brasileira e o Almanack Laemmert, já exaustivamente analisadas, o jornal intitulado $O$ Vulgarizador é uma rica fonte para a compreensão do público de ciência, além de ainda ser pouco conhecido.

No mesmo período havia jornais que se dedicavam exclusivamente às mulheres, como o Echo das Damas, Órgão Dedicado aos Interesses da Mulher (literário e científico), de Amélia Carolina da Silva Couto. Em um de seus artigos, lemos: "A mulher de hoje também estuda, também pensa, sabendo conhecer o que é útil e o que é mau para família. Ela também quer o progresso, também quer o engrandecimento da humanidade, pela realização das idéias modernas" (Editorial, 1880, p.1). A idéia de que mulheres estudam e pensam está presente também n'O Vulgarizador, como iremos demonstrar ao longo deste artigo. Contudo o nosso desafio será desenvolver uma análise de gênero partindo das imagens produzidas por um jornal ilustrado. 
É interessante notar que esse jornal via a própria imprensa como um artefato da modernidade, como o vapor e a eletricidade (Bondivenne, 1877, p.82). O status moderno do jornal não se devia apenas ao fato de ele divulgar novas idéias, como um veículo de civilização; ele próprio era produto das inovações tecnológicas de sua época. Em um artigo de 1877 O Vulgarizador afirmava que era recente, no Brasil, o processo de ilustração de livros e jornais, pois que estes eram gravados a mão. Com o advento do processo fotográfico, porém, poder-se-ia, a partir daquele momento, transportar a imagem para uma chapa de zinco ou cobre. Os $12^{\circ}$ e $17^{\circ}$ números do jornal trouxeram imagens produzidas a partir do novo processo, chamado de Leggo de Nova York e utilizado pelo jornal The Graphic, onde trabalhava o desenhista George Hartt, irmão do geólogo Charles Hartt (Um lago..., 1877, p.89, 133). ${ }^{1}$

Segundo Walter Benjamin (1975), uma das conseqüências do processo de industrialização foi a transformação da aura da obra de arte, devido à da reprodução em larga escala. Um dos fatores que contribuíram para tal mudança foi o surgimento do jornal ilustrado, por afetar a forma de apropriação imagética, tornando-a "humanamente mais próxima" (p.15). Ainda segundo Benjamin, "os jornais ilustrados começam a se apresentar como indicadores de itinerários"; as imagens junto com os textos se tornam um todo, e deixa de ser possível olhálas isoladamente, pois são as séries que constroem o significado que se deseja comunicar para o público. Assim, as imagens seriadas são meios para instruir sobre as novidades do mundo moderno e o modo de consumi-las (p.19). Ao nos determos nas imagens, vimos surgir uma sensibilidade moderna quanto à apropriação imagética, estabelecida a partir da relação entre textos (legendas) e imagens. Com as gravuras da ciência e da tecnologia não era diferente, e suas imagens tornavam-se objetos de consumo e entretenimento, com o propósito de modelar a visão corrente de modernidade e, por conseqüência, o comportamento das pessoas.

Narrar a história da divulgação da ciência a partir de imagens ainda é uma abordagem pouco explorada no Brasil. O uso das imagens como documento propõe novas dimensões à interpretação da história, permitindo aprofundar a compreensão do universo simbólico. O presente estudo, particularmente, leva a uma exploração mais profunda da relação entre ciência e cultura ${ }^{2}$, já que partimos da premissa de que para 'ler' uma imagem é preciso estar atento a seus signos e sua produção, desenredando as relações existentes entre diferentes elementos (cf. Meneghel, Abberg, Bastos, maio-ago. 2003).

Em nossa primeira imagem, que é um anúncio do jornal (Figura 1), estão presentes os principais elementos explorados no decorrer deste artigo. A gravura é tão emblemática que foi a única a se repetir ao longo da vida de $O$ Vulgarizador. Na edição de dezembro de 1877, a imagem ilustra a matéria "As vias de comunicação antigas e modernas" (As vias..., 1877). A leitura do quadro de assuntos nos ajuda a ver que o jornal se dedicava aos "grandes problemas da ciência", indo da astronomia à ciência aplicada na indústria e no comércio. Logo abaixo desse quadro lê-se a informação de que o jornal é redigido por "homens da ciência e estudiosos". Na mesma página, a preocupação com o público feminino pode ser percebida em uma representação da chegada de um trem de ferro, símbolo de civilização e progresso naquele momento. Assim, a página traz uma divisão orientada pela categoria de gênero: os 'homens da ciência' e as mulheres que fariam parte do público. Aqui começa a se desenhar a figura feminina proposta pelo jornal, que se mantém em todas as demais 
imagens: pelas roupas, inferimos que se trata das mulheres pertencentes aos segmentos urbanos, empolgadas com as inovações de seu tempo. Interessante notar que, nesse jornal, elas serão geralmente representadas nos espaços públicos. Outra característica marcante das gravuras d'O Vulgarizador é a presença de figuras masculinas identificadas, a exemplo dos retratos de Graham Bell e do Pai Tomás, apenas para citar os que aparecem em nossa série. As mulheres, contudo, são anônimas e geralmente representadas como parte do público.

Na Figura 1 também observamos a bandeira dos Estados Unidos. Indício de outra preocupação deste trabalho: mostrar que os Estados Unidos estavam presentes no imaginário brasileiro como modelo de progresso e avanço, tanto na indústria como no comportamento. Segundo Lia Osório Machado (1995), os nossos intelectuais do século XIX viam os norteamericanos em geral como pouco civilizados frente aos padrões europeus, mas ao mesmo tempo como fundadores de uma civilização técnica que ameaçava a supremacia européia. Isto produziria a "idéia de que foi o tecnicismo e a ruptura com o intelectualismo europeu que permitiu aos norte-americanos fortalecerem o sentimento de nacionalidade" (p.340). A imprensa do final do século XIX está repleta dessa visão dos Estados Unidos como novo modelo para o Brasil. A título de exemplo, apenas um, lembramos o artigo publicado na Revista Brasileira, no qual encontramos a afirmação de que o velho continente, com sua aristocracia hereditária e despotismo militar, era obscurantista e preso às instituições do passado: "Neste ponto nós os analfabetos, nós os tupinambás somos os civilizados" (GamaRoza, 1880, p.19). Para aquela geração, lucraríamos mais se estivéssemos atentos a um país eminentemente progressista como os Estados Unidos e o seu "povo-Prometeu" (p.19).

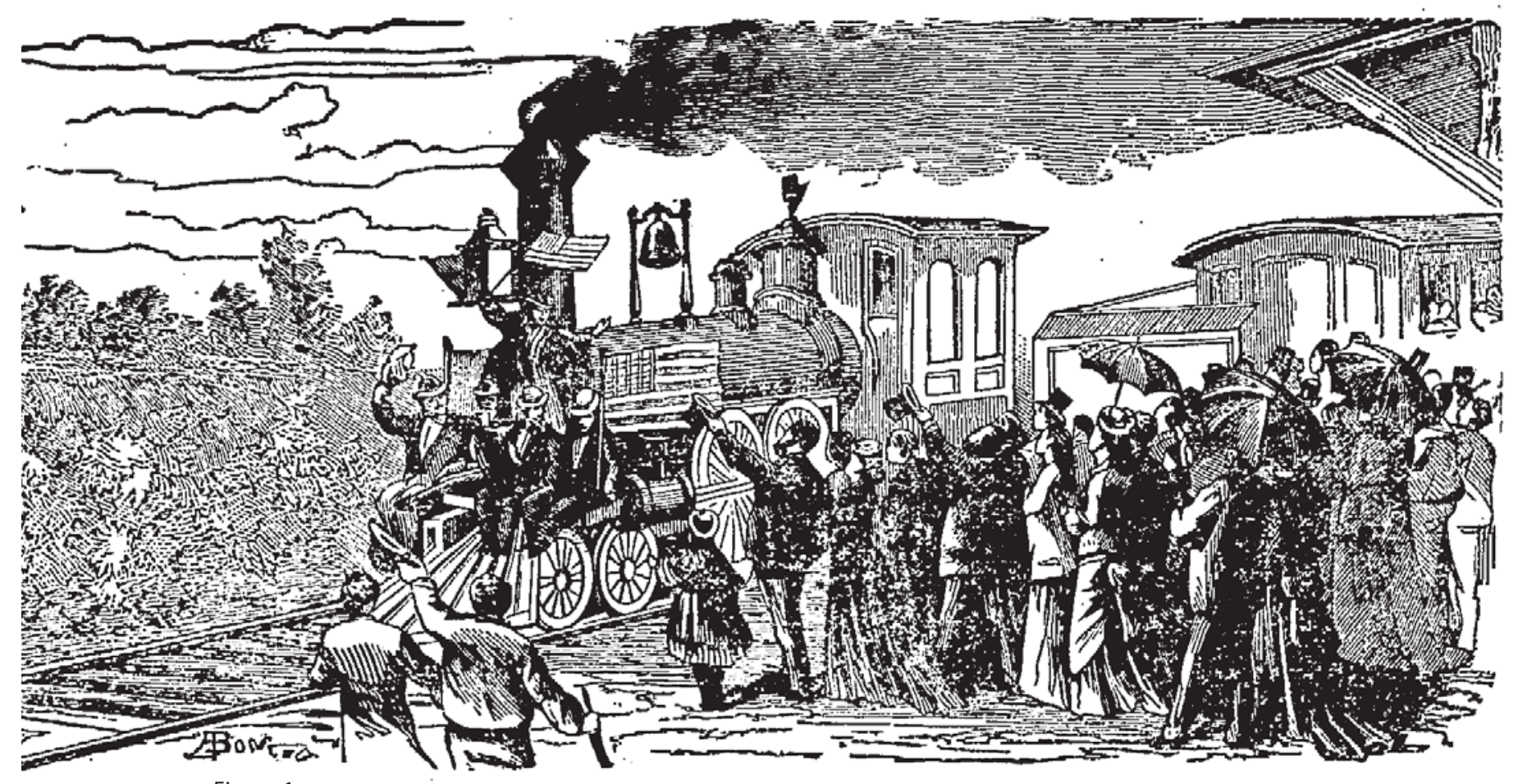

Figura 1 
Sem dúvida alguma, um momento crucial de manifestação da força do "povo-Prometeu" foi a Exposição de Filadélfia, realizada em 1876 para celebrar o centenário da independência norte-americana. O imperador esteve lá e, segundo o Relatório da Comissão Brasileira (Brasil, 1877), ele estudava "com grande interesse as glórias americanas no vasto campo da indústria e da instrução" (p.4). A idéia de que a Exposição de Filadélfia era uma oportunidade de aprendizado estava presente no relatório oficial, como também na imprensa, que via com desânimo a participação brasileira no evento: "Os Estados Unidos, cujo desenvolvimento industrial é surpreendente, abre suas portas a todos os expositores do globo ... cujos resultados, o efeito que por toda parte tem produzido, anunciam-os de grande alcance material e moral. Ao Brasil também caberá algum benefício nessa festa da indústria" (A Exposição..., 10 ago. 1876, p.3).

Em 1875 Zaluar publicou várias reportagens para O Globo sobre a Exposição Nacional Brasileira, ou seja, a preparatória para a de Filadélfia. Nossa hipótese é de que o entusiasmo de Zaluar pelas grandes exposições fez que ele levasse os seus ideais para $O$ Vulgarizador. Assim, ler o jornal era uma forma não apenas de visitar as exposições, mas também de reforçar, junto ao público, o otimismo quanto à ciência e à tecnologia, presente nos textos e imagens. Procurava-se portanto a combinação entre instrução e entretenimento, principal característica, à época, de práticas de divulgação da ciência, ou, para usar um termo de então de vulgarização.

Observemos a Figura 2, em cuja legenda lê-se: "Cabana de colonos nos sertões da América (Exposição de Filadélfia)". Essa gravura, que ilustra o número de maio de 1878, pode estar ali simplesmente para cumprir a promessa do editor de veicular uma imagem em cada edição.

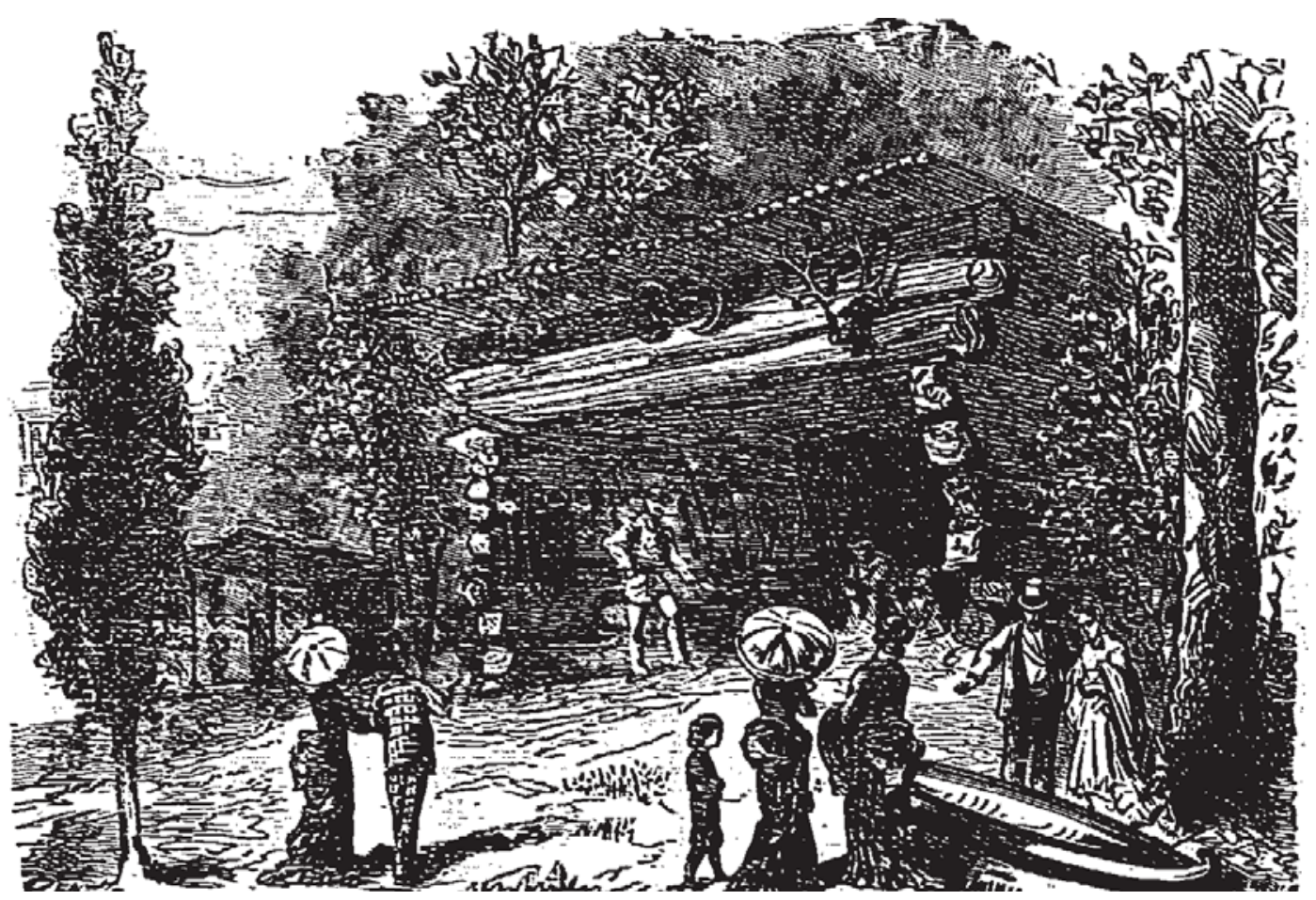

Figura 2 
O texto aparentemente não corresponde à imagem de um estande da Exposição da Filadélfia representando o interior dos Estados Unidos, pois se trata de uma elegia ao geólogo americano Charles Frederic Hartt, importante nome da história da institucionalização da geologia no Brasil (Figueirôa, 1997). Apesar do contraste entre a amenidade da gravura e o teor do artigo - a morte do geólogo -, essa página nos remete a um tipo de associação intelectual entre o Brasil e os Estados Unidos, concretizada pelos trabalhos de Hartt, ou seja: a excepcionalidade da natureza brasileira como subsídio para a moderna ciência norte-americana. Zaluar (1878) afirma que "o professor Hartt amava sinceramente o Brasil" (p.163) e contribuiu em muito para o desenvolvimento das ciências naturais nacionais.

Na Figura 2 observamos também a distribuição equilibrada de casais. Destaca-se, no centro e abaixo, uma família com uma criança supostamente acompanhada por seus pais. Mais acima vê-se uma figura masculina que parece guiar o restante do grupo. Aqui vemos um tema que se repetirá nas demais imagens: as atividades instrutivas deveriam ser feitas pelo casal. Suzanne Sheffield (2004) afirma, em seu texto sobre as mulheres e a educação científica promovida em um periódico inglês entre 1860 e1890, que havia um apelo ao ideal romântico de educação científica, na qual a mulher acompanha o marido; em outras palavras, que a instrução nas ciências da natureza colaboraria para a harmonia da vida doméstica, uma vez que era realizada em conjunto por ambos os sexos (p.20). A gravura sugere que as mulheres deveriam participar da mesma "atividade intelectual do homem de nosso tempo", mostrando a intenção de Zaluar (1878) ao afirmar que "as penumbras do infinito, procura conhecer pelos efeitos a origem das causas misteriosas que regem os mundos físicos, tirando de todos estes audazes cometimentos solução prática aplicável ao bem estar da existência humana..." (p.162).

Ainda no contexto das Exposições, na imagem que ilustra o artigo "Os faróis" (Figura 3), vemos uma única mulher visitando um estande com uma inovação tecnológica de sua época: um farol de orientação náutica, cujo texto afirma que "a nossa gravura representa um desses faróis do sistema mais moderno" (Os faróis, 1878, p.145). A imagem possui os já citados elementos recorrentes em nossa série: a origem da gravura é norte-americana e ilustra uma mulher acompanhada por um cavalheiro e admirando as inovações técnicas. Ao realizar a análise da série de imagens é fundamental notar as repetições para verificar os elementos mais consistentes que se queria transmitir ao público. Outro ponto que se repete é a ambiência da ação pictórica em Exposições. Consideradas 'escolas práticas', ou melhor, um lugar de instrução e de lazer, elas eram o lugar privilegiado para o contato do público com objetos de ciência e tecnologia, no qual se manifestava a confiança pelas recentes conquistas da sociedade burguesa (cf. Cazelli, Marandino, Studart, 2003, p.87). Nas Exposições eram vistos, sem muita diferenciação, tanto os instrumentos científicos ${ }^{3}$ quanto as inovações tecnológicas. Essas imagens eram representativas do progresso científico e tecnológico daquele tempo e assumiam a função de materialização de uma cultura científica mais geral e abstrata no cotidiano da sociedade brasileira. O esforço de popularizar esses objetos pode ser interpretado como o desejo da época em modernizar o Brasil, desde a economia até os costumes. Logo em seguida à gravura do farol há a da "Estátua da Liberdade" (Figura 4), e nela observamos os mesmos signos: os Estados Unidos, as mulheres participando da cena e a idéia de construções colossais que impressionam e são por si mesmas a manifestação do poder humano. 


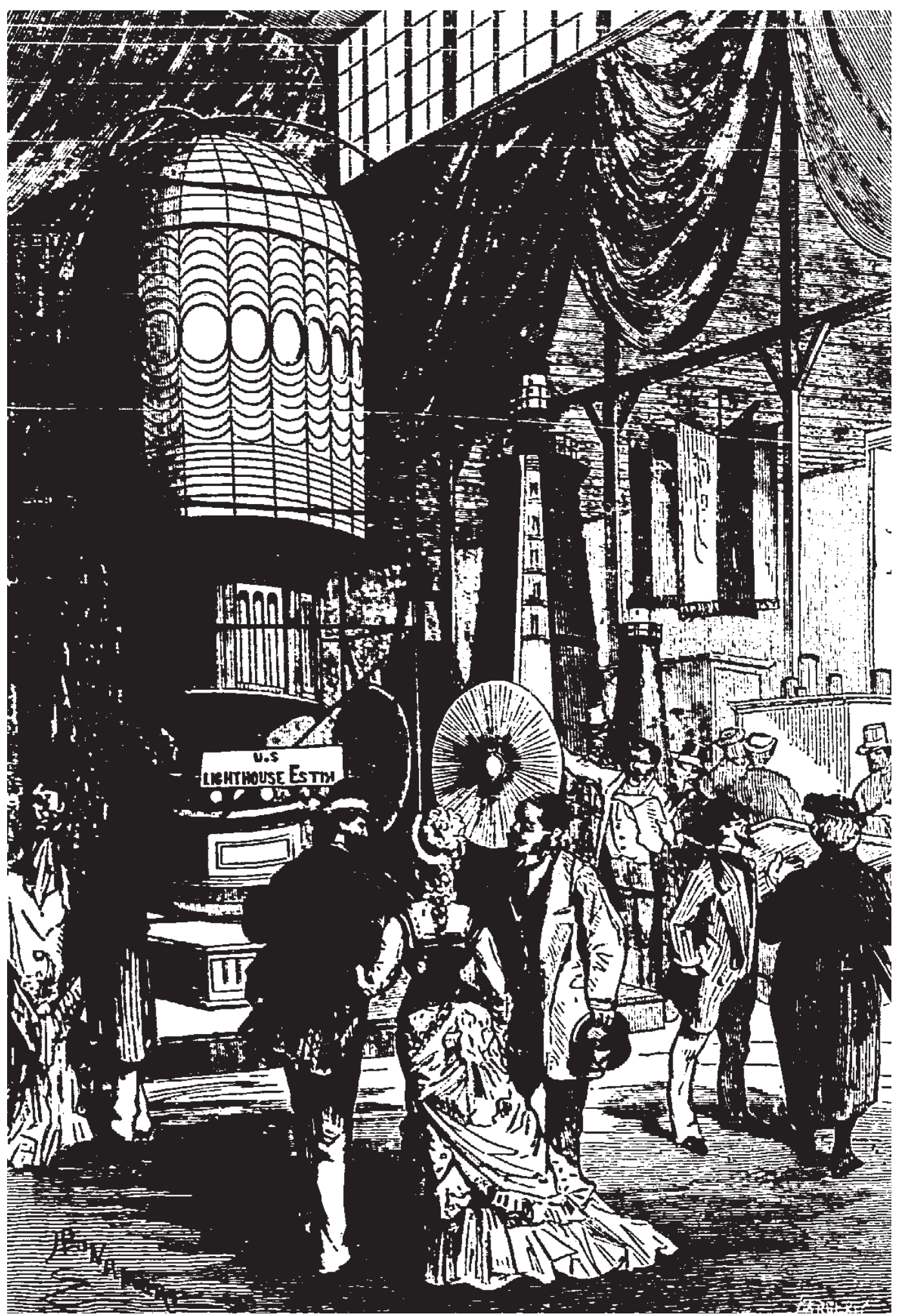

Figura 3 


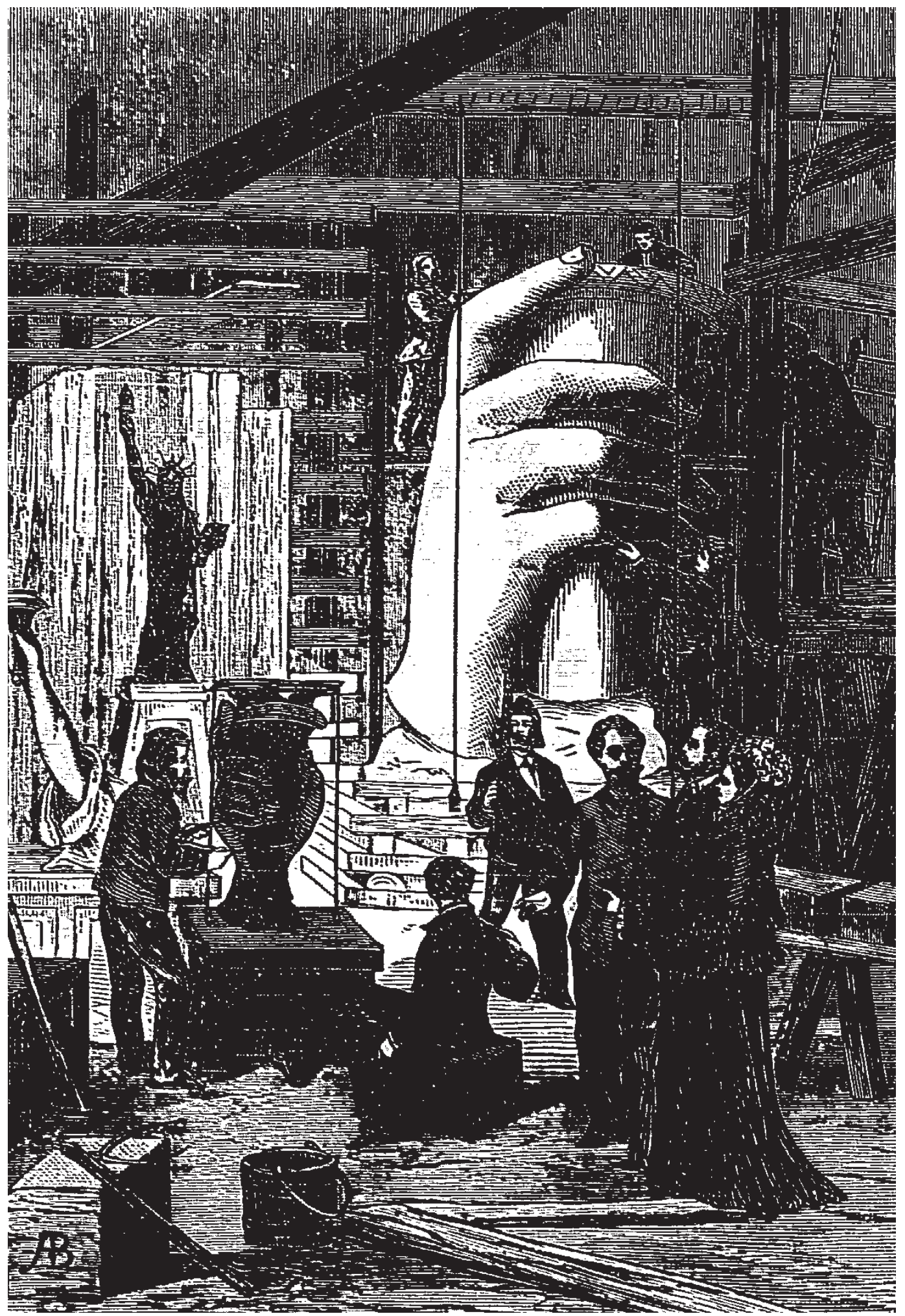

Figura 4 
Para ilustrar a relação entre exposição, tecnologia e imprensa, podemos citar a invenção do telefone, que teve grande destaque na Exposição de 1876, bem como no periódico. Neste vemos estampas da conferência de Graham Bell em Salem e dos componentes de seu aparelho. Para explicar o seu funcionamento foi reproduzida em O Vulgarizador uma notícia, já publicada na Ilustração Brasileira por Miguel Antonio da Silva, então professor da Escola Politécnica do Rio de Janeiro, a qual descrevia a teoria e o mecanismo de "tão importante combinação físico-mecânica". O título da matéria era "O electro-telefone" (Figura 5), e o aparelho era visto como "maravilhosa invenção do telégrafo falante". Tanto quanto explicar o funcionamento deste, a matéria queria noticiar "a conferência do professor Bell e o lugar onde se achavam as pessoas testemunhas do resultado deste assombroso invento" (O Electrotelefone, 1877, p.57). A respeito desse invento, pode-se afirmar que ele constituiu uma das inúmeras aplicações do principal campo de investigação da física experimental do século XIX, o eletromagnetismo. Tal conhecimento conduziria a uma série de inventos de aplicação prática: o desenvolvimento dos motores e geradores elétricos para trens e bondes, o suprimento de eletricidade pública, bem como o telégrafo elétrico e, nas mãos de um inventor como Alexander Graham Bell, o telefone. O eletromagnetismo representou a resolução de um problema da física teórica sobre o modo pelo qual a eletricidade e o magnetismo podiam afetar um ao outro no espaço vazio: o problema da ação a distância (Ronan, 1987, p.50).

Na gravura em que Graham Bell apresenta seu invento ao público, o que nos chama a atenção é a participação de uma mulher na demonstração do sistema telefônico (observar os vários fios que atravessam a imagem) e, na audiência, a forte presença feminina. O papel do

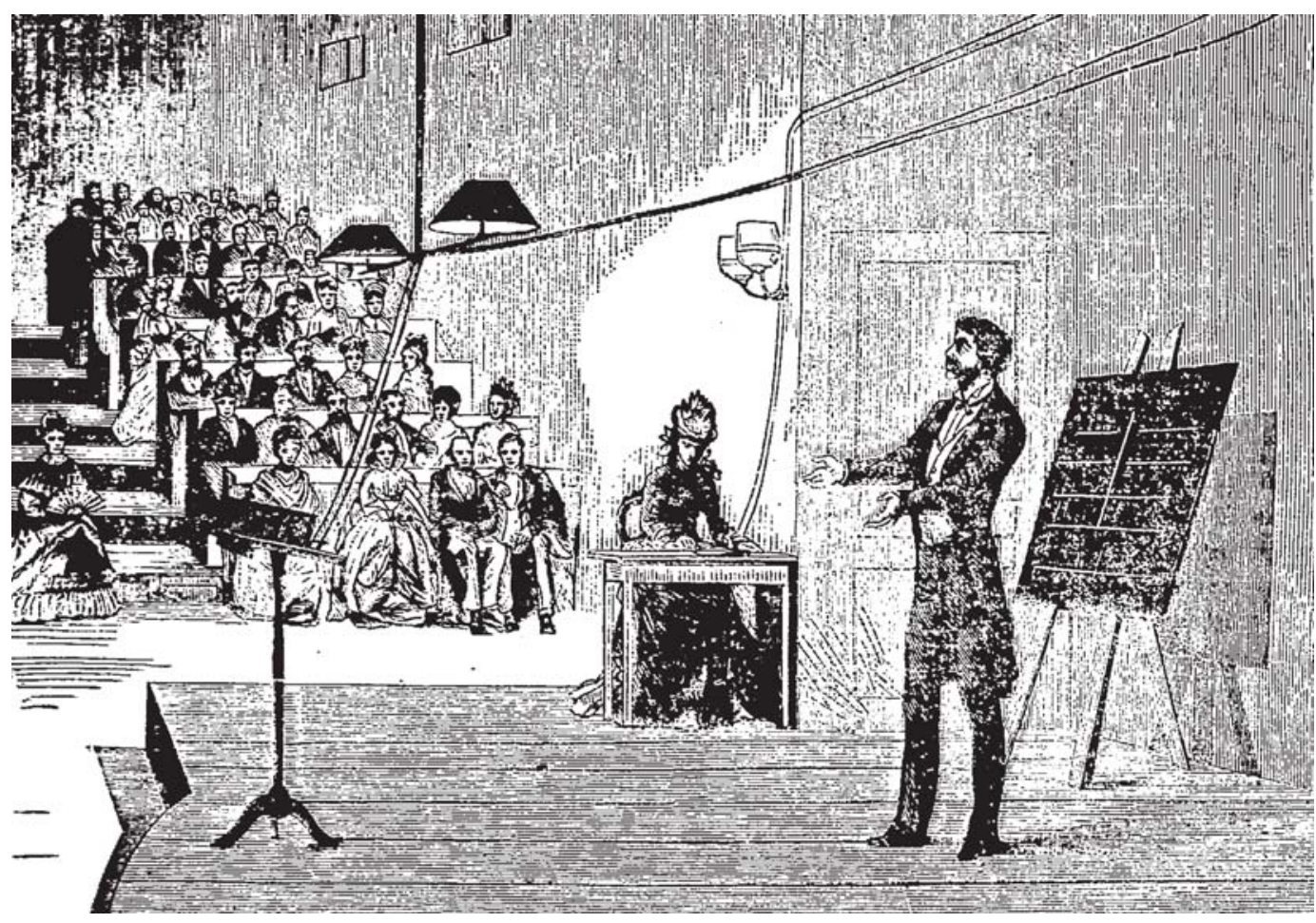

Figura 5 
testemunho foi fundamental para a consolidação da prática científica no século XVII com os experimentos públicos, como os ocorridos na Royal Society de Londres. O trabalho de Schaffer e Shapin (1985) mostra como a ciência experimental, ao nascer, precisava da presença de um grupo de pessoas respeitáveis como testemunhas, por conta do valor da evidência na construção da ciência como um discurso de verdade. Nesse sentido, a gravura retrata a função da vulgarização no século XIX diferentemente dos períodos anteriores, uma vez que a validação, a partir dali, passaria pela revisão entre os pares no âmbito da comunidade cientifica, transformando o público em espectadores a serem informados a respeito dos resultados obtidos pelos especialistas. A presença feminina na audiência pode ser interpretada como a presença de agentes a presenciarem admiradas e a instruírem-se sobre as novas práticas.

Quanto às experiências com esse novo aparelho, o artigo noticia que haviam sido realizadas em Boston e em Salem (como mostra a gravura). Sabe-se que a demonstração prática para o imperador brasileiro Pedro II, ocorrida durante a Exposição de Filadélfia, foi fundamental para acelerar a introdução do invento no Brasil. Em 1877, Pedro II "fez instalar linhas telefônicas interligando o Palácio da Quinta da Boa Vista às residências de seus ministros, incumbindo a empresa Western and Brazilian Telegraph de realizar a tarefa (Magalhães, 1994, p.317).

O uso do telefone por Pedro II, na Exposição de 1876, foi bastante comentado na imprensa da época, até mesmo por seus adversários, como o literato José de Alencar. Em seu jornal $O$ Protesto, Alencar afirmava que a frase proferida pelo imperador na 'máquina que fala' foi "To be or not to be" (citado em Lira Neto, 2006, p.25). N'O Vulgarizador não há referências ao imperador na Exposição, mas em números subseqüentes o jornal voltou a citar o telefone. No ano seguinte, o aparelho foi descrito como um fenômeno que impressionou na Exposição Industrial Fluminense, uma vez que as "maravilhosas experiências" mostraram-no "indispensável auxiliar em quase todas as circunstâncias da vida doméstica e social" (Exposição..., 10 ago. 1879, p.250).

A leitura d'O Vulgarizador nos ajuda a compreender como a vida doméstica estava sendo afetada pela 'revolução' que a ciência e a técnica estavam a promover. A relação entre mulheres e o espaço doméstico foi sendo construída ao longo da história e, naquele momento, já era algo dado pela cultura. Interessante ver como no primeiro parágrafo do artigo "Fogões americanos de Casserls" (Figura 6) se faz a relação entre a ciência moderna e as conquistas mecânicas e industriais, repercutindo na casa: "O espírito indagador da ciência moderna auxiliando a audácia das concepções mecânicas e industriais tem produzido uma verdadeira revolução não só nos instrumentos de trabalho e por conseqüência no aumento das forças produtoras, mas até, o que ainda é mais admirável nos nossos próprios usos domésticos" (Fogões..., 1878, p.234).

O novo fogão é apresentado como um instrumento que viabilizaria os modernos conselhos da medicina e higiene para combater as doenças: "Reconhecendo-se que os maus alimentos e a sua defeituosa preparação, eram causa de muitas enfermidades, que afetam especialmente o aparelho digestivo, procurou-se obviar a estes inconscientes, vigiando não somente a natureza dos alimentos e más condições de salubridade, como fabricando utensílios apropriados..." (Fogões..., 1878, p.234). 
Além de suas qualidades higiênicas, o fogão de Cassels foi visto como um avanço nas "investigações científicas e industriais". Diz o artigo: "foi preciso primeiramente estudar o modo de espalhar com igualdade e por toda parte simultaneamente calor de combustível" (Fogões..., 1878, p.235). Esse fogão americano seria, assim, superior ao inglês, "que sempre teve primazia na qualidade e na solidez de seus artefatos de ferro", mas que "um dia encontrou nas exposições modernas um rival". $\mathrm{O}$ artigo noticia que esse invento ganhara a medalha de ouro na Exposição de Paris de 1878.

Após a década de 1870, a ciência se tornou mais próxima da sociedade brasileira, com a proliferação de instituições científicas e o incremento de suas atividades, tais como cursos públicos, revistas e exposições. Segundo Fabíola Rohden (2003), "a ciência virava moda e era cultuada nos jornais e nos romances naturalistas. Nas cidades, a onda de programas de higienização e saneamento contribuía para este movimento" (p.39).

Glenna Matthews (1987) nos mostra que o impacto da industrialização, nas casas norteamericanas do século XIX, representou um declínio do poder das mulheres da elite no espaço doméstico em comparação à América colonial, na qual a casa era um lócus essencial de produção para a sociedade. A 'revolução' doméstica com fogões, máquinas de costura e comidas industrializadas, os quais ajudavam a diminuir a carga do trabalho doméstico, segundo Matthews contribuiu para esvaziar o lar do seu papel transcendente na cultura. Ele se torna oposto aos valores capitalistas da esfera pública e assim perde o espaço central que

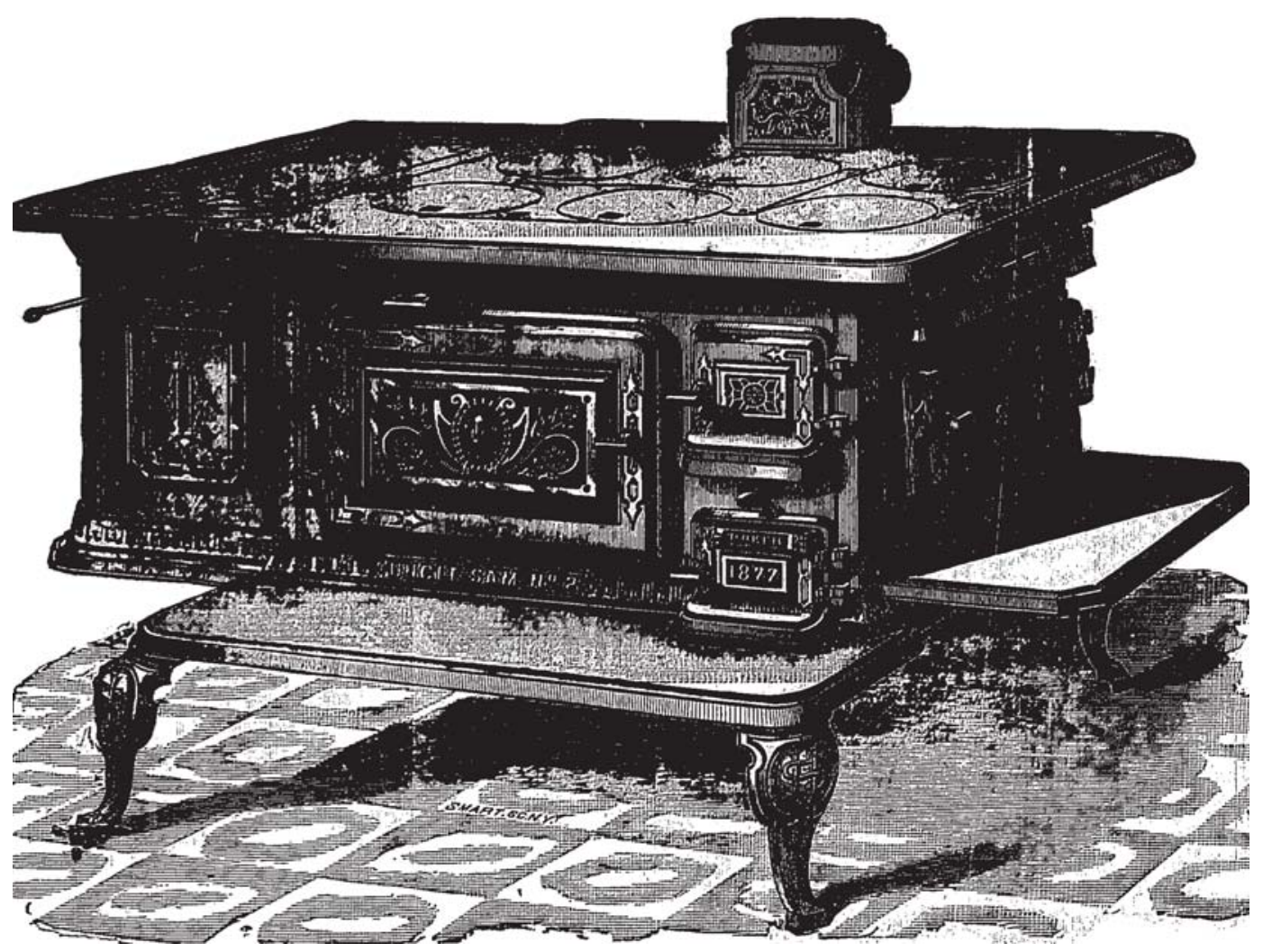

Figura 6 
ocupava na sociedade do século XVIII, não só como unidade econômica mas também como lugar de formação do cidadão, apesar do esforço de vários reformadores do século XIX.

O caso brasileiro, entretanto, contrasta com a experiência norte-americana. A mulher branca na sociedade colonial tinha a função de fornecer filhos legítimos para a família brasileira. A maioria dos relatos afirma que a dona da casa brasileira procurava parecer pouco engajada nos afazeres domésticos, por conta da aversão ao trabalho, própria da sociedade escravista. O ideal de comportamento feminino, na Colônia e no começo do século XIX, era o recato e a reclusão no espaço doméstico, salvo para participar das procissões, missas e festas religiosas (Leite, 1984).

A partir do processo de urbanização das cidades brasileiras, na segunda metade do século XIX, a mulher ganhou as ruas. Importante lembrar que as ruas da cidade do Rio de Janeiro, no século XVIII, eram insalubres e não havia regras definidas de ocupação do espaço. No século seguinte, observamos a implementação de políticas públicas baseadas em medidas higiênicas, fazendo que as ruas da cidade pudessem ser mais facilmente percorridas pelas senhoras (D'Incao, 1997). Assim, podemos ver que os processos de urbanização e industrialização ajudaram a produzir um novo significado para a figura feminina, que passou a ser alvo dos projetos modernizantes da sociedade.

A sociedade brasileira daquele período estava se transformando em vários aspectos. Para a geração que produzia periódicos como $O$ Vulgarizador, era evidente e inevitável o fim da escravidão. A discussão do tema girava em torno das formas de substituição da mão-deobra escrava. Bastante ilustrativo é artigo de Silvio Romero (1881) na Revista Brasileira, no qual afirma: "aqui não há escravocrata" (p.203). Esse 'espírito abolicionista' pode ser visto no artigo "O trabalho" (1877), d'O Vulgarizador, onde se lê que quem olha para as "maravilhas do trabalho e da indústria moderna não pode duvidar da lei eterna e ascendente do progresso!". Isto se devia às "descobertas científicas [que] engenharam mecanismos e adaptaram mais energéticos motores aos produtos aperfeiçoados da indústria e das artes, entre os povos e as nações civilizadas" (p.81). O exemplo a seguir era das fábricas de Manchester e de Glasgow. O autor conclui seu texto apregoando as virtudes do trabalho operário, que "facilita o bem estar a todas as classes sociais, com esplendor e lustre da civilização". A gravura que ilustra esse artigo (Figura 7) é de "uma dessas operárias desconhecidas" (p.82). A relação entre texto e imagem produz uma sensação contraditória no(a) leitor(a), pois embora o artigo afirme que a mulher da gravura é uma operária, não se vêem máquinas ou teares que denotem o ambiente das fábricas. Temos aí uma mulher executando um trabalho manual de costura, tradicionalmente desenvolvido no espaço doméstico. Talvez o editor tenha feito uma 'colagem' e utilizado o recurso do texto para incluir o que faltava à ilustração, levando o público a 'ler' a gravura como representação de uma operária.

Talvez Zaluar não quisesse apenas a libertação dos escravos conforme ao "espírito civilizador europeu" e também ao norte-americano. Não por acaso, há no jornal um artigo sobre o reverendo Geosia Henson (Figura 8), homem que inspirou o romance de Henriqueta Beecher Stowe, A cabana de Pai Thomaz, de grande importância para o fim da escravidão nos Estados Unidos (O Pai Thomaz, 1878, p.209). Por essa escritora pode-se conhecer a relação entre as mulheres brancas e a escravidão nos Estados Unidos. Quando 
indagada sobre os motivos que a levaram a escrever o livro, Stowe respondeu: "Eu escrevi porque, como mulher, como mãe, me sentia oprimida e com o coração partido com a dor e a injustiça que via" (citado em Matthews, 1987, p.50).

No Brasil, as mulheres também tiveram destaque na luta abolicionista. Therezinha Collichio (1988) afirma que a partir de 1869 a eclosão da propaganda abolicionista fez constantes apelos aos sentimentos humanitários, os quais ecoaram entre as mulheres brasileiras e fizeram aumentar o "acesso das senhoras às conferências e aos comícios" (p.44).

Uma das mais fortes manifestações abolicionistas do jornal é a gravura "A Estátua do Liberto" (Figura 9), sobre cuja procedência não temos informações precisas. Contudo, como ela sucede o artigo sobre Pai Thomaz, supomos que seja uma imagem norteamericana. No centro há um escravo liberto a empunhar um livro, sugerindo que sua liberdade se deve à lei. A imagem descreve todas as etapas da escravidão. Ao fundo, notamos um velho vestido de forma destoante do grupo, caracterizado portanto como escravo. No canto direito vemos um casal de negros vestidos como burgueses (e calçados, o que significava não serem escravos) a observar a cena. À esquerda notamos um grupo de crianças; um dos meninos segura um livro, o que indica ter sido alfabetizado. A imagem de 1878 não é um retrato dos negros brasileiros daquela época, mas talvez uma projeção do

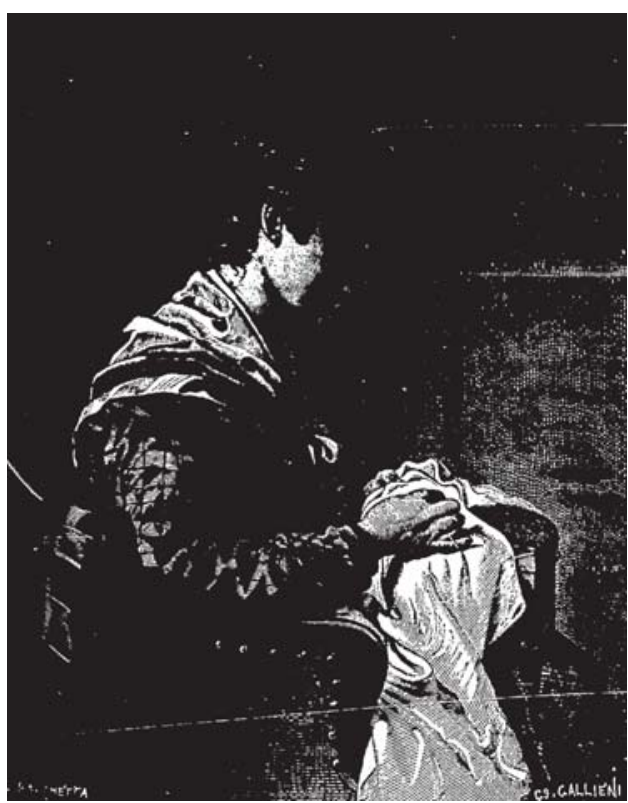

Figura 7

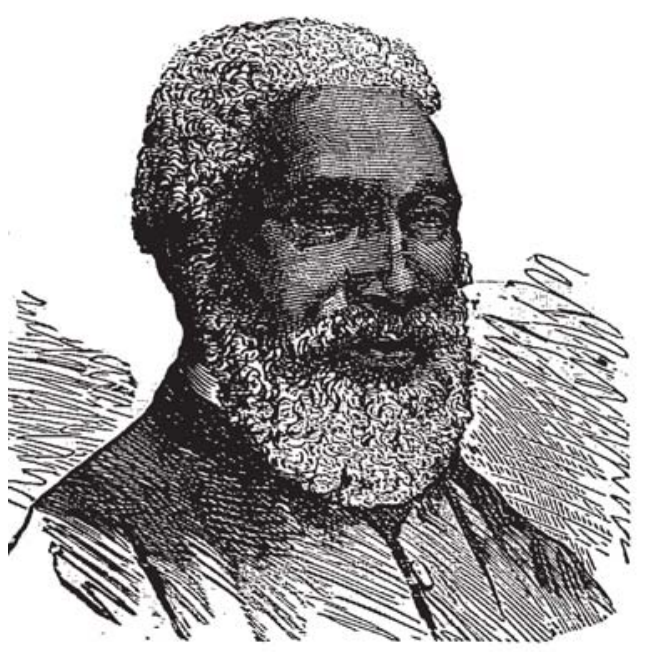

Figura 8 que eles deveriam ser. Os elementos da imagem se articulam como frases a compor um texto.

Por último, analisaremos uma imagem que, vista sob certos aspectos, poderia ser considerada um 'ponto fora da curva' em nossa série. É a gravura que ilustra a edição de novembro de 1877: "O busto de Wagner" (Figura 10). Nela observamos uma mulher vestida com roupa de gala, admirando extasiada o busto de Wagner. Ela repousa a mão esquerda no peito, sugerindo um estado de espírito repleto de emoção. O texto nos informa que a cena acontece na grande sala da Filarmônica de Roma. O compositor é apresentado da seguinte forma, n'O Vulgarizador: 


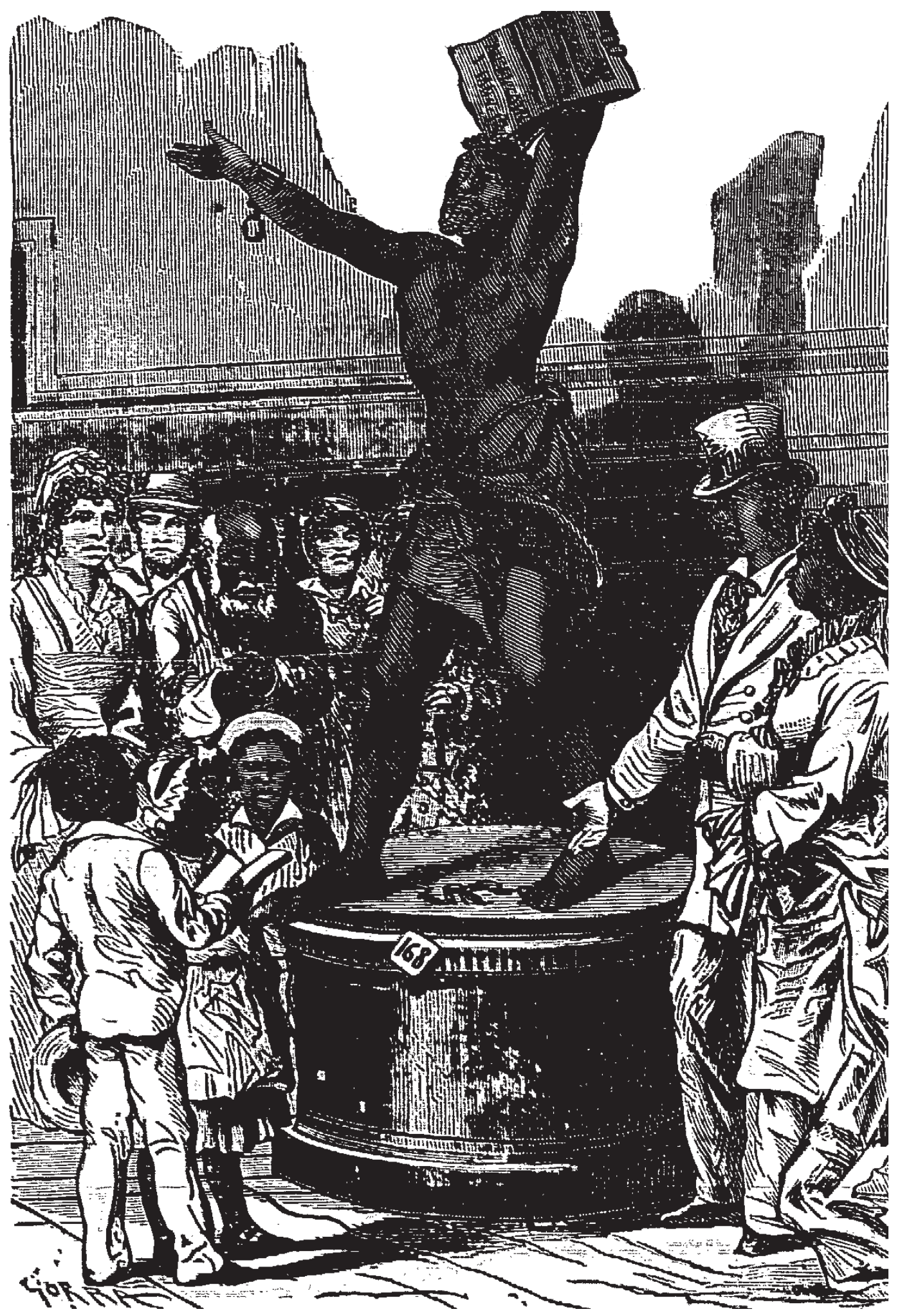

Figura 9 
Desprezando simultaneamente a escola clássica e a escola romântica, Wagner apresenta-se como um inovador, e empreende audazmente escrever as primeiras estrofes do hino musical do futuro.

A temeridade de Wagner, se por um lado encontra fervorosos adeptos, não é também poupada pela crítica violenta e por vezes demasiada de seus adversários apaixonados. (O busto..., 1877, p.105; grifos meus)

A relação de gênero se faz presente, na imagem, no olhar da mulher para o objeto (o busto), formando uma dinâmica de complementaridade entre masculino e feminino. A mulher pode ser identificada com o público que observa o 'gênio' da música. A posição de subordinação ocupada na cena remete à idéia de um público a ser instruído e formado pelos grandes vultos do pensamento ocidental. Ao fundo, há uma figura masculina que não participa da ação principal. Aparentemente de passagem, confere à gravura um sentido de movimento e transitoriedade, próprio da noção de modernidade daquele momento.

A gravura nos leva a indagar sobre a presença do compositor alemão naquele jornal dedicado à divulgação da ciência e dos "conhecimentos úteis". Um dos possíveis motivos consiste no reconhecimento da relação entre ciência e cultura: segundo uma concepção iluminista, a civilização seria alcançada com a educação dos sentidos, produzida pela arte, e com os avanços materiais da ciência. O elemento diferenciador que separaria arte e ciência estaria na controvérsia produzida pelos admiradores e críticos de Wagner, uma vez que, para eles, a expressão artística era o lugar privilegiado da subjetividade e da emoção. Nas páginas d'O Vulgarizador, a ciência era apresentada como expressão de uma racionalidade única e incontestável, produtora de um discurso de verdade inquestionável. Contudo há uma constante, tanto nos textos que noticiam a ciência como nesse sobre música, de que o futuro é construído pelas inovações. Essa idéia é o que Koselleck (2006) chama de concepção moderna de história. Quando a diferença entre experiência do passado e expectativa do futuro aumentou progressivamente, sobretudo após a Revolução Francesa, o passado deixou de servir de modelo para a solução dos problemas do presente. Assim, se por um lado a política tornou mais evidente o rompimento entre experiência e expectativa, foi o progresso técnico-industrial que trouxe a certeza de que as invenções e descobertas científicas iriam criar um novo mundo: "Ciência e técnica estabilizaram o progresso como sendo a diferença temporal progressiva entre experiência e expectativa" (p.320).

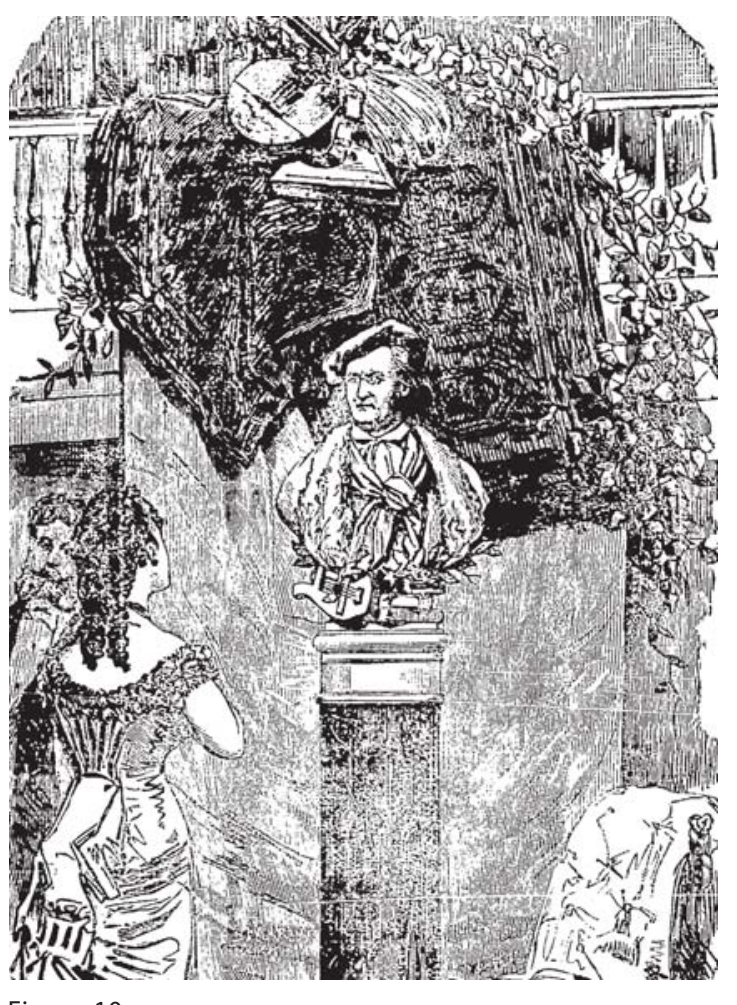

Figura 10 
Naquele momento a força norteadora das idéias científicas era inegável e estava determinando, por exemplo, o que a sociedade entendia por raça, povo e nação. As relações de gênero também sofriam influência desses conceitos, e o espaço de atuação das mulheres seria definido pelas teorias científicas do higienismo, positivismo e darwinismo. ${ }^{4}$ Assim, no final do século XIX começava a existir uma expectativa de uma 'mulher ilustrada', responsável tanto pela saúde quanto pela educação dos filhos. Os papéis sociais de cada gênero também seriam determinados por meio de arquétipos: homens seriam seres de maior competência intelectual e mulheres, seres afetivos e frágeis, a serem guiadas e supervisionadas pelos homens até mesmo na vida adulta. Um bom exemplo são as mulheres da série de gravuras aqui estudada, as quais transitavam nos espaços públicos para assistir a uma conferência ou para ver uma exposição, sempre acompanhadas por um homem.

No caso brasileiro do século XIX, o futuro não é apenas um ponto na escala temporal; ele é representado também pela distância geográfica. A partir da abordagem evolucionista da época, as nações européias e, como destacamos no presente estudo, os Estados Unidos ocupariam o lugar almejado pelo Brasil, ou seja, nesses lugares o futuro já havia chegado. Para aquela geração estava claro que havia um roteiro a seguir e ele passava pelas relações sociais, não só pela industrialização. Acompanhando o fim da escravidão, as mulheres deveriam passar a participar das transformações da sociedade brasileira. Sem dúvida, a série de imagens vistas aqui estava formando indicadores de itinerários, conceito retomado de Benjamin. Itinerários a serem seguidos pelas mulheres brasileiras a fim de que o país atingisse o mais rápido possível o seu devido lugar "no concerto das nações civilizadas".

\section{AGRADECIMENTOS}

Agradeço ao CNPq o apoio à pesquisa e a Marcos Guedes Veneu seus comentários e leitura atenta.

\section{NOTAS}

${ }^{1}$ Charles Hartt foi nomeado chefe da Comissão Geológica do Brasil, em 1875, pelo imperador, e morreu em 1878 no Rio de Janeiro, vítima da febre amarela.

2 Para a questão 'história e imagens' ver, entre outros, Freitas, jun.-dez. 2004, e Kossoy, jan.-dez. 1993.

${ }^{3}$ Para mais informações, ver Heizer, 2000.

${ }^{4}$ A relação entre darwinismo e gênero n'O Vulgarizador já foi por mim abordada, em Vergara, 2004.

\section{REFERÊNCIAS BIBLIOGRÁFICAS}

\section{Jornais e revistas do século XIX}

A EXPOSIÇÃO...

A Exposição de Filadélfia. Imprensa Industrial, Rio de Janeiro. 10 ago. 1879.

As VIAS...

As vias de comunicação antigas e modernas. $O$ Vulgarizador, Rio de Janeiro, n.16, p.121. 1877.

BONDIVENNE, L.

A imprensa. O Vulgarizador, Rio de Janeiro, n.11, p.82-84. 1877.
BRASIL.

Comissão da Exposição Centenária de Filadélfia. O Império do Brasil na Exposição Universal de 1876 em Filadélfia. Rio de Janeiro: Tipografia Nacional. 1877.

EDITORIAL.

Echo das Damas, Rio de Janeiro, n.1, p.1. 1880. 
FOGÕES...

Fogões americanos de Casserls. O Vulgarizador, Rio de Janeiro, n.30. 1878.

GAMA-ROZA, Francisco.

A educação intelectual. Revista Brasileira, Rio de Janeiro, tomo 3. 1880

O BUSTO..

O busto de Wagner. O Vulgarizador, Rio de Janeiro, n.14. 1877.

\section{O ELECTRO-TELEFONE.}

O Vulgarizador, Rio de Janeiro, n.8, p. 57-59. 1877.

\section{O PAI THOMAZ.}

O Vulgarizador, Rio de Janeiro, n.27. 1878.

Os FARÓIS.

O Vulgarizador, Rio de Janeiro, n.19. 1878.

O TRABALHO.

O Vulgarizador, Rio de Janeiro, n.11, p.81. 1877.

\section{Obras gerais}

BENJAMIN, Walter.

A obra de arte na época de suas técnicas de reprodução. In: Benjamin, Horkheimer, Adorno, Habermas: textos escolhidos. São Paulo: Abril Cultural. p.9-34. (Os Pensadores, 48). 1975.

CAZELLI, Sibele.; MARANDINO, Martha.; STUDART, Denise.

Educação e comunicação em museus de ciência: aspectos históricos, pesquisa e prática. In: Gouvêa, Guaracira.; Marandino, Martha.; Leal, Maria Cristina (Org.). Educação e museu: a construção social do caráter educativo dos museus de ciência. Rio de Janeiro: Acess; Faperj. p. 83-106. 2003.

COLLICHIO, Therezinha A.F.

Miranda Azevedo e o darwinismo no Brasil. Belo Horizonte: Itatiaia. 1988.

D’INCAO, Maria Ângela.

Mulher e família burguesa. In: Del Priore, Mary (Org.). História das mulheres no Brasil. São Paulo: Contexto. p.223-240. 1997.

FIGUEIRÔA, Sílvia.

As ciências geológicas no Brasil: uma história social e institucional, 1875-1934. São Paulo: Hucitec. 1997.

FOX KELLER, Evelyn.

Making a difference: feminist movement and feminist critiques of science. In: Creager, A.; Lunbeck, E.; Schiebinger, L. (Ed.). Feminism in twentieth-century science, technology, and medicine. Chicago: The University of Chicago Press. p.98-109. 2001.

\section{QUESTÃO RELIGIOSA.}

Echo das Damas, Rio de Janeiro, ano 1, n.6. 3 ago. 1880.

ROMERO, Silvio.

A questão do dia: emancipação dos escravos. Revista Brasileira, Rio de Janeiro. 1881.

UMA REUNIÃO...

Uma reunião instrutiva. O Vulgarizador, Rio de Janeiro, n.10. 1877.

\section{UM LAGO...}

Um lago no Interior de Nova York. $O$

Vulgarizador, Rio de Janeiro, n.12, p.89-90. 1877.

ZALUAR, Augusto Emílio.

O professor C.F. Hartt. O Vulgarizador, Rio de Janeiro, n.21, p.161-163. 1878.

ZALUAR, Augusto Emilio. Exposição Nacional de 1875. Rio de Janeiro: Tipografia Globo. 1875.

FREITAS, Artur

História e imagem artística: por uma abordagem tríplice. Estudos históricos, Rio de Janeiro, n.34. jun.-dez. 2004.

HEIZER, Alda.

Os instrumentos científicos e as grandes exposições do século XIX. In: Heizer, Alda.; Videira, Antonio Augusto Passos.(Org.). Ciência, civilização e impérios nos trópicos. Rio de Janeiro: Access. 2000.

KOSELLECK, Reinhart.

Futuro passado: contribuição à semântica dos tempos históricos. Rio de Janeiro: Ed. PUC-Rio. 2006.

KOSSOY, Boris.

Estética, memória e ideologia fotográficas. Acervo, Rio de Janeiro, v.6, p.13-24. jan.-dez. 1993.

LEITE, Miriam Moreria.

A condição feminina no Rio de Janeiro do século XIX. São Paulo: Hucitec. 1984.

\section{LIRA NETO.}

O inimigo do rei: uma biografia de José de Alencar. São Paulo: Globo. 2006.

LOPES, Maria Margaret.

Sobre convenções em torno de argumentos de autoridade. Cadernos Pagu, Campinas, n.27, p.35-61. jul.-dez. 2006.

MACHADO, Lia Osório.

Origens do pensamento geográfico no Brasil: meio tropical espaços vazios e a idéia de ordem 
(1870-1930). In.: Castro, Ina Elias de; Gomes, Pedro Cesar da Costa; Corrêa, Roberto Lobato (Org.). Geografia: conceitos e temas. Rio de Janeiro: Bertrand Brasil. p.309-353. 1995.

MAGALHÃES, Gido.

Telecomunicações. In: Vargas, Milton (Org.). História da técnica e da tecnologia no Brasil. São Paulo: Editora da Unesp. p.315-342. 1994.

MATTHEWS, Glenda.

Just a housewife: the rise \& fall of domesticity in America. New York: Oxford University Press. 1987.

MENEGHEL, Stela N.; ABBERG, Claíde; BASTOS, Ronaldo.

'Os vivos são sempre e cada vez mais governados pelos mortos': um estudo exploratório sobre desigualdades no morrer. História, Ciências, Saúde - Manguinhos, Rio de Janeiro, v.10, n.2, p.686-687. maio-ago. 2003.

ROHDEN, Fabiola.

$A$ arte de enganar a natureza: contracepção, aborto e infanticídio no início do século XX. Rio de Janeiro: Ed. Fiocruz. 2003.
RONAN, Colin A.

História ilustrada da ciência da Universidade de Cambridge: a ciência nos século XIX e XX. São Paulo: Círculo do Livro. 1987.

SCHAFFER, Simon; SHAPIN, Steve.

Leviathan and the air-pump: Hobbes, Boyler and the experimental life. New Jersey: Princeton University Press. 1985.

SHEFFIELD, Suzanne L.M.

The 'empty-headed beauty' and the 'sweet girl graduate': women's science education in Punch, 1860-90. In: Henson, Louise et al. (Ed.). Culture and science in the nineteenth-century media. Burlington: Ashgate. 2004.

VERGARA, Moema R.

Cartas a uma senhora: gênero e a questão da divulgação do darwinismo no Brasil. Trabalho apresentado no 3. Colóquio Internacional História do Darwinismo na Europa e Américas, Manaus. 2004. 